\title{
“Caverão vírus, esse mata mais do que a COVID-19!": sistema de justiça e seus regimes de desumanização em lugares chamados de Favela.
}

\author{
"Caverão vírus be caused, this kills more than COVID-19!": \\ Justice system and its dehumanization regimes in places called \\ Favela.
}

Gabriel Borges da Silva ${ }^{1}$

\section{RESUMO}

A proposta abordará a produção sistemática de mortes em lugares chamados de favela. Pesquisas anteriores me possibilitaram pôr em evidência justificações que eram utilizadas para tais mortes, centradas nas moralidades acerca de quem morre e quem pode matar. Em suma, as mortes são justificadas na conduta do indivíduo que morreu, como no caso da ideia de "deu mole", que mobiliza um sistema de crenças a respeito. Com a pandemia, devido a COVID-19, tais localidades motivaram preocupação a respeito dos impactos da doença. Os moradores seguem até o momento suas vidas, pela necessidade de trabalhar ou em função da inadequada prestação de serviços de saúde. No jogo de quem pode ou não morrer, trabalhadores necessitam pegar conduções e se expor nas ruas. Enquanto problema de saúde pública, na percepção de muitos interlocutores a COVID-19 parece uma ameaça distante, ao passo que as práticas de violência estatal continuam produzindo mortes. A temática acerca das percepções sobre saúde pública, violência estatal e cidadania é o que pretendo investigar.

\section{PALAVRAS-CHAVE:}

Vírus, Morte, Vida, Cidadania, "dar mole".

\begin{abstract}
The proposal will address the systematic production of deaths in places called favelas. Previous research has enabled me to highlight the justifications that were used for such deaths, centered on the moralities about who dies and who can kill. In short, deaths are justified in the conduct of the individual who died, as in the case of the idea of "giving soft", which mobilizes a belief system about it. With the pandemic, due to COVID-19, such locations have raised concerns about the impacts of the disease. Residents live their lives up to the moment, due to the need to work or due to the inadequate provision of health services. In the game of who may or may not die, workers need to pick up driving and expose themselves on the streets. As a public health

1 Doutor em Sociologia e Direito pela Universidade Federal Fluminense, Mestre em Direito Constitucional pela Universidade Federal Fluminense. Atualmente, Professor Substituto na Universidade do Estado do Mato Grosso UNEMAT.
\end{abstract}


problem, in the perception of many interlocutors, COVID-19 appears to be a distant threat, while practices of state violence continue to produce deaths. The theme about perceptions about public health, state violence and citizenship is what I intend to investigate.

\section{KEYWORDS:}

Viruses, Death, Life, Citizenship, “dar mole”.

\section{INTRODUÇÃO}

No presente artigo pretendo abordar um sistema de produção de mortes em lugares chamados de favela (SILVA, 2019) que já venho discutindo em meus trabalhos. Nesse sentido, a ideia de favela deve ser observada a partir do questionamento em relação a quão genérica pode ser. Conformes pesquisas, não somente no Rio de Janeiro, mas em diversos outros Estados do Brasil, podemos perceber que "a favela não existe" (SILVA, 2019). Evidentemente que tal classificação recai sobre diversas áreas da cidade do Rio de janeiro. No entanto, em sua perspectiva redundante e que, por vezes, me parece ser reveladora de uma percepção que qualquer lugar chamado de favela é igual.

O Vale ${ }^{2}$, por exemplo, lugar chamado de favela aonde desenvolvi a maior parte da minha pesquisa para o doutorado (2014-1019), não cumpre o estereótipo de um morro ou de um lugar degradado. Pelo contrário, se estabelece em uma área plana que por anteriormente ser uma parte da cidade ocupada por fazendas e sítios, provem de uma divisão de terrenos grandes, sobre os quais foram construídas casas que crescem para o alto. Antigos moradores com quem pude conversar e que tem ao menos 70 anos morando no Vale, me relataram que toda área que hoje tem casas e ruas, era de árvores e pequenos rios, mas que principalmente de 1980 para cá essa configuração começou a mudar. Em minha pesquisa para doutorado não observei de perto conflitos em relação ao chamado "direito de laje", conforme observado por Correa (2008, p. 995 - 1116), mas ouvi algumas histórias de problemas familiares e disputas que realmente remetiam a valores morais sobre quem teria o direito a respeito da "laje". Afinal, apesar de

\footnotetext{
${ }^{2}$ Nome fictício em razão de preservar as identidades e histórias que descrevo em minhas pesquisas.
} 
ainda existirem casas grandes, esse crescimento para o alto e a divisão de terrenos dividiu gerações familiares e contribuiu de alguma forma para a aproximação da vida cotidiana. Fator que me despertou preocupação quando soubemos da pandemia em relação a COVID-19.

Estabeleci o movimento para observar tais relações a partir desse novo normal que engloba a questão da COVID-19. De fato, ao desenvolver a pesquisa a respeito da produção de mortes em um conflito estabelecido aparentemente entre a polícia e traficantes, mas que engloba várias dimensões que não cabem nessa proposta, pude perceber que a maioria das mortes no Vale, nesse contexto de conflito, não são contempladas ou sequer contestadas em nosso sistema de justiça. Evidentemente que por diversos fatores, que a meu ver ampliam a necessidade de pesquisas empíricas que coloquem o direito em diálogo com a realidade, e a questão da cidadania seja observada em sua perspectiva prática. Ao passo que se torna um ponto central para a reflexão a respeito da vida e da morte. Não pretendo aqui discorrer somente via perspectiva estritamente jurídica e tampouco aprofundar em uma revisão bibliográfica ou produção de um estado da arte a respeito. No entanto, a relação da cidadania \& trabalho x vida \& morte, se confunde com a "fé de que tudo ficará bem" entre os moradores do Vale ou a própria ideia de que "cada um se cuida da maneira que pode". Ao mesmo tempo que todo cenário vislumbrado em relação a pandemia também causa preocupação via a percepção de que o "bicho está pegando em relação ao vírus e tá todo mundo ligado nisso". Conforme me disse Jonas, importante interlocutor para a construção do recorte aqui proposto.

A continuidade dessas práticas de produção de morte pela atuação policial durante a pandemia, também me fizeram querer entender como e para quem se distribui a garantia da proteção do direito à vida em um momento como esse. Apesar de não me utilizar de dados quantitativos, irei traçar um paralelo entre o impacto, na percepção dos moradores do Vale, da COVID-19 e as ações policiais que tive notícia em diálogo com meus interlocutores. Inicialmente, me vali de notas de caderno de campo produzidas entre 2015 e 2019 para a construção da tese (SILVA, 2019). A época eu morava no Vale e por meio de uma participação observante realizei diálogos com os crias (SILVA, 2019) do Timor Leste (uma das esquinas do Vale, na qual desenvolvi meu trabalho de campo), partilhando seus movimentos, relações e justificações para a recorrente morte de seus colegas.

Desta feita, comecei a conversar a respeito dos impactos da pandemia e a levantar informações sobre as mortes pelo vírus. Afinal, de acordo com notícias que circulavam nas redes sociais na época, a região da cidade em que o Vale se localiza tinha os maiores índices de 
morte por COVID-19 da Cidade do Rio de Janeiro³ ${ }^{3}$ Com o apoio interdisciplinar, valendo-me da minha formação em Ciências Sociais e Direito, busquei observar quais questões envolviam as conformações a respeito de quem terá o direito à vida garantido e para quem o fato de não morrer se tornará uma dádiva.

Do ponto de vista metodológico, cabe esclarecer que o fato de ser morador de um lugar chamado de favela produz impacto no meu entendimento e olhares enquanto pesquisador. Certamente, houve a necessidade de realizar um distanciamento do objeto. Para tanto, em minhas observações participantes me vi imerso naquele universo, conversei com meus interlocutores, acompanhando seus movimentos, relações e justificações para a morte. Para este artigo, respeitando as recomendações oficiais, comecei a pesquisa conversando por meio das redes sociais disponíveis via aplicativos de celular a respeito dos impactos do Corona Vírus. Procurei entender questões que parecem envolver um processo de desumanização frequente nos lugares chamados de favelas, bem como isso impacta na saúde pública.

A desumanização do sistema de justiça disponível para tais sujeitos explicita um estado caótico de saúde que repercute uma habitual forma de se deixar morrer para aqueles que não possuem tratamento de saúde igualitário. Então com a pesquisa de campo desenvolvida até o momento, pude refletir a ideia de como a produção sistemática de mortes é próxima a realidade daquelas pessoas. O Corona Vírus fora anunciado "como um vírus de todos", portanto no imaginário das pessoas que conversei é uma questão de sorte ou asar adquirir a doença. Como um interlocutor que me disse: “- Poxa pego ônibus lotado para ir e voltar do trabalho. Entrego mudança de bacana. De que adianta eu ficar trancado em casa? Só jogar na mão de Deus mesmo e seguir o baile!"

Por outro lado, a especificidade do caverão $^{4}$ que declaradamente não é para todos,

3 Vide notícias de veículos de informação a respeito dos casos de COVID 119 na Zona Oeste do Rio de Janeiro: 1. https://g1.globo.com/rj/rio-de-janeiro/noticia/2020/12/18/barra-da-tijuca-e-o-bairro-com-mais-casos-de-covid19-no-rio-desde-o-inicio-da-pandemia-dia-prefeitura.ghtml; https://www.cnnbrasil.com.br/nacional/2020/05/01/rj-mortes-por-covid-19-reforcam-desigualdade-entre-bairrosda-cidade; 3. https://www.brasildefato.com.br/2020/08/05/maioria-das-mortes-por-covid-no-rio-e-de-moradoresdos-bairros-mais-pobres-diz-ipea; $4 . \quad$ http://www.rio.rj.gov.br/web/transparencia/coronavirus; 5 . https://www.data.rio/datasets/dados-individuais-dos-casos-confirmados-de-covid-19-no-munic\%C3\%ADpio-dorio-de-janeiro-2; $\quad 6 . \quad$ https://covid.saude.gov.br/; 7. https://www.ipea.gov.br/portal/index.php?option=com_content\&view=article \&id=36266:a-tribunal-covid-19mata-mais-na-periferia-do-que-em-bairros-nobres-do-rio-de-janeiro\&catid=131:sem-categoria\&directory $=1$; (última visualização em 20/03/2021)

4 O veículo blindado da Polícia Militar do Rio de Janeiro. Tem a estética de um carro forte, com janelas que permitem que apenas os armamentos fiquem expostos. Sua pintura é toda preta. O início desse equipamento que se assemelha a um tanque de guerra se deu pelo Batalhões de Operações Especiais da Policia Militar - BOPE. No 
reafirma que tal tratamento do Estado é próximo e concreto na vida dessas pessoas, como me disse um rapaz num dos grupos de redes sociais ao falar do "caverão vírus". Afinal, como me fora afirmado "o caverão vírus" pega mesmo. Assim, a dificuldade em relação a direitos a saúde, já conhecida dos moradores do Timor Leste, somada a proximidade da morte, que se justifica no infortúnio de quem morreu por conta da violência estatal, parecem repercutir na ideia de que o "Corona Vírus não é isso tudo não!". Enfim, "quem tiver que morrer vai morrer mesmo".

No período de dezembro de 2020, retornei ao Rio de Janeiro e com isso pude observar de perto as dinâmicas do Vale. Como afirmei, possuo relações familiares naquele contexto, tais relações conjecturaram fatores que me estimularam a morar novamente no Vale nesse momento de pandemia. Tal movimento também foi importante para o desenvolvimento deste artigo. Portanto, resolvi organizar a narrativa seguindo esse movimento, primeiramente com as questões desenvolvidas via redes sociais em contraponto com as observações promovidas com o retorno ao Rio de Janeiro.

\section{OBJETIVO DA PESQUISA}

Como referido, a questão da produção sistemática de mortes e os regimes morais de justificação de tais mortes são problemáticas que norteiam meus recentes trabalhos de pesquisa. De fato, havia observado relações conflituosas entre os atores do sistema de justiça penal e os moradores do Vale. Inclusive daqueles que atuam no contexto do tráfico de drogas que se estabeleceu na região nos últimos 30 anos (SILVA, 2019).

Com o advento da pandemia e ciente das diversas formas de se morrer e se deixar morrer que observei no Vale. Comecei a refletir a respeito do então "novo" vírus. Ou seja, em uma região que a morte é normalizada e constituída de diacríticos que encerram no morto a justificativa para morte, qual seria o impacto dessa pandemia. Com isso, tracei como objetivo entender as percepções dos meus interlocutores a respeito das mortes produzidas pelo vírus. 
A partir dos diálogos iniciais, parecia que tais mortes não aparentaram um impacto (ao menos na percepção das pessoas) significativo, quando se observava todas as dificuldades e violências impostas habitualmente aos moradores do Vale. Com isso, procurei entender como as pessoas estavam lidando com as mortes anunciadas e concretizadas pela pandemia. Por conta das provocações de meus interlocutores e também de todo caminho que venho desenvolvendo em minhas pesquisas, resolvi fazer isso em diálogo de como as pessoas nesse momento de pandemia estão lidando com as incursões do caverão no Vale. Afinal, o caverão, tal qual é chamado pela maioria dos moradores no Vale, não parou de fazer suas incursões e tampouco de produzir mortes em nenhum momento da pandemia, segundo o que pude observar e de acordo também com o relato dos meus interlocutores.

\section{METODOLOGIA}

No momento que iniciei a pesquisa que desbocou na construção dos dados aqui apresentados, eu estava no Mato Grosso, na Cidade de Barra do Bugres aonde sou professor substituo na UNEMAT (Universidade do Estado do Mato Grosso). Fiquei lá até o final do ano de 2020, quando retornei para o Rio de Janeiro. Continuo exercendo atividades on line em relação a função de professor. No entanto, com esse retorno a pesquisa e a minha "quarentena" em relação ao vírus foi significativamente afetada. Quando estava no Mato Grosso, iniciei um diálogo constante com amigos, parentes e interlocutores no Rio de Janeiro, principalmente moradores do Vale. Com isso, as redes sociais e grupos de whatsapp (uma das mídias sociais mais utilizadas para contatos virtuais pelos meus interlocutores) se tornaram além de ferramentas, fontes importantes para o desenvolvimento da pesquisa.

Como referi, para o desenvolvimento da minha tese de doutorado (SILVA, 2019) morei no Vale e estabeleci relações com os moradores e vizinhos para além das já estabelecidas em meu cotidiano de "cria de favela" (SILVA, 2019). A participação observante ou observação participante, bem na linha de Foote-White (2005) ditaram a construção dos dados. No entanto, com diferenças em relação ao trabalho do autor, já que a ideia de favela não me era algo estranho ou exótico. Pelo contrário, ao longo da pesquisa pude percebe que a "esquina" me era mais familiar ou me foi, durante a maior parte das relações que desenvolvi ao longo da minha vida. 
Com o material produzido no doutorado em mente e com os contatos no telefone celular dos meus interlocutores, me utilizei novamente do whatsapp como fonte de pesquisa (SILVA, 2019). Assim, comecei a provocar e cobrar meus interlocutores em relação a seus hábitos e práticas sociais em um momento de pandemia. Dessa "cobrança”, surgiram diálogos nos quais demostrei meu interesse de pesquisa bem como as tensões que vislumbrava naquele momento de início de pandemia no ano de 2020. No entanto, por questões alheias a pesquisa, retornei ao Rio de Janeiro e fui morar novamente no Vale. Com isso, retomei relações de proximidade construídas ao longo da pesquisa, bem como me vi reconstruindo minha relação com a quarentena e a ideia de isolamento. Apesar de não estar totalmente nas ruas, passei a encontrar pessoas e de alguma forma viver uma vida social novamente no Vale.

Desta feita, a construção metodológica do presente artigo de alguma forma envolve primeiramente um movimento de preocupação em relação aos meus interlocutores, amigos e familiares no Rio de Janeiro. Depois, passa por um momento de entendimento das questões e das vivencias desses atores, porém ainda a distância, não somente pelo isolamento social imposto, mas pelo fato de eu estar em outra cidade. E, por fim, termina com o contraste vivido por mim ao retornar ao Rio de Janeiro e tomar contato efetivamente de perto das questões observadas. Portanto, utilizarei relatos para descrever as problemáticas encaradas por meus interlocutores, bem como buscar produzir questões do ponto de vista jurídico e na construção de um objeto sociológico (LENOIR, Remi, 1998).

\section{4. “O QUE A GENTE NÃO PODE FAZER É DEIXAR DE TRABALHAR!"}

Jonas de 33 anos é auxiliar de serviços gerais e um "pai de família" como ele mesmo se apresenta. Para chegar ao seu trabalho que é em um condomínio de luxo em uma zona isolada da Cidade do Rio de Janeiro, ele chega a levar até 2 horas e 30 minutos do seu dia, tanto para ir quanto para voltar. Eu pude acompanhar a história de Jonas bem de perto. Quando o conheci na esquina do Timor Leste ele estava desempregado. Para sustentar suas duas filhas, uma de 3 e outra de 7 anos, ele fazia uma série de "bicos”. Exercia funções de pedreiro, montador, lavador de carros e até mesmo de garçom em festas de 15 anos e casamento. No entanto, nem sempre conseguia o suficiente para arcar com seus custos. Tudo que ele ganhava ia para suas filhas e 
esposa e por vezes precisava da ajuda de amigos e parentes para obter as coisas para si próprio.

Durante esse período que passou desempregado (foram quase 2 anos) ele vivia estressado. Por vezes, como me relatou, ficava desesperado e em casa nos momentos de solidão chegava até a chorar. Pensava em suas dívidas, no futuro de suas filhas e se no amanhã teria o sustento necessário para elas. Como ele não teve pai, dizia para mim que a maior honra da vida dele era não deixar as meninas passando necessidade. Após muita procura e muitas negativas, conseguiu esse emprego de auxiliar de serviços gerais, ganhando 1 salário mínimo com sua Carteira de Trabalho assinada. Fator que conforme demonstra Gomes (2005) se tornou uma dádiva construída através do movimento do trabalhismo e da valorização da figura do "homem trabalhador" no período da ditadura Vargas. Então, apesar de o serviço ser bem pesado, Jonas demonstrava muita satisfação pelo fato de agora estar empregado.

O condomínio é tão grande que segundo ele se perdia de vista. Na realização de suas tarefas chegava a andar quilômetros empilhando lixo dos moradores e separando materiais para reciclagem em um único dia. Nos primeiros meses de trabalho chegou a emagrecer quase 10 quilos. Fato que não passou despercebido por seus colegas do Timor Leste, que tratavam seu emagrecimento com jocosidade. Sua resposta era sempre a mesma: "pode zoar à vontade, graças a Deus tô empregado, papai do céu abençoou e não tenho do que reclamar. Tô ralando igual um condenado, mas pelo menos tenho o meu pão de cada dia e não tá faltando nada para minha família!"

Assim que começou a pandemia, Jonas postou uma foto no grupo de whastapp dos "crias do Timor Leste". Na foto estava em um bar conhecido na região bebendo uma cerveja e na legenda da foto disponibilizada pelo aplicativo do celular, colocou a seguinte frase: "corona vírus é o caralho, aqui é tudo nosso na paz do senhor! ”. Jonas não era da igreja, como os outros frequentadores daquela esquina. No entanto, como todos que circulavam ali, a fé e a percepção a respeito da ideia de divino passavam por uma perspectiva cristã.

Após lançar a foto, começaram uma série de gozações. Os outros rapazes, passaram a dizer que ele ia morrer; que ia pegar a COVID 19; que não era para ninguém chegar perto dele. Passadas as trocas de mensagens jocosas, um dos rapazes que ali morou, mas atualmente era policial disse: "essa porra não mata ninguém não, agora os maconheiro ai do grupo se ficarem dando mole por ai vão é tomar tapa na cara da polícia”. Com isso aconteceu mais uma rodada de gozações, que pautavam a corrupção policial e momentos da infância de todos. Como eu era 
o participante mais deslocado daquele grupo e fora inserido por um dos rapazes no começo da minha pesquisa nos idos de 2015, tinha que tomar cuidado ao entrar na jocosidade, pois os signos e códigos de intimidade nem sempre eram por mim entendidos.

Passados mais alguns dias, em um final de semana o Jonas postou uma foto no baile funk, com a seguinte legenda: “aqui não tem coronga não rapá pode vir que tá tudo palmeado!”. Logo em seguida, alguns rapazes iniciaram brincadeiras jocosas e outros colocaram fotos tomando cerveja e brincando com a questão do vírus. A esta altura eu já estava desesperado com as notícias e a falta de informação sobre a COVID-19. Esse dia foi próximo a tudo que estava acontecendo na Europa em países como a Itália. Por conta de toda tragédia mundial que se apresentava, não resisti e comecei a colocar notícias sobre as mortes, bem como escrevi a seguinte frase: "vocês só podem estar de brincadeira, vocês não estão vendo tudo que está acontecendo? É pra geral ficar em casa, agora tem gente até indo pro baile! Vocês não têm amor as suas vidas não? $"$

A minha fala gerou nova discussão no grupo. Um dos rapazes que era entregador de mudanças foi o primeiro a responder: "tá pensando que todo mundo é professor igual a você Gabriel que pode ficar em casa?’. Pensei. Pronto! É agora que vão me retirar do grupo. Então insisti, que tinha noção da realidade, mas que "ir para o baile funk já era demais". Dessa provocação, eu questionei a preocupação com eles mesmos e com os outros. Foi quando a conversa tomou um tom menos jocoso e alguns dos rapazes expuseram seus pontos de vista.

Jonas mandou um áudio bem grande, no qual explicou sua opinião. Começou dizendo que eu já estava chato para caramba, que todo mundo tinha televisão em casa e que todo mundo sabia o que estava acontecendo. Aliás, como eu já referi, que para ele chegar ao trabalho pegava o trem da rede ferroviária carioca, o BRT (linha de ônibus expresso que traça parte da Cidade do Rio de Janeiro) e ainda pegava mais um ônibus em direção a seu destino final. Jonas terminou o áudio dizendo:

“porra vê se tem cabimento, não tenho como parar de trabalhar, lá no condomínio aumentaram nossa jornada de trabalho, porque os morador tão tudo em isolamento, pego condução lotada, agora na hora do meu lazer vou ter que ficar trancado em casa? Mano me desculpa isso não faz sentido nenhum... O que eu não posso é parar de trabalhar e aqui se a gente tem que ter medo de algo é do caverão vírus porra!" 
A colocação de Jonas foi importante para que que eu pudesse entender que, se por um lado havia uma crítica ao fato das pessoas no Vale não estarem fazendo quarentena. Por outro lado, a percepção sobre a quarentena e as relações de trabalho faziam bastante sentido nas lógicas locais. Inclusive apontavam para uma sociedade desigual ao ponto de pessoas terem que trabalhar mais, não necessariamente em serviços essenciais, para manter privilégios e a tranquilidade daqueles que podiam permanecer em isolamento. Fatores marcantes na desigualdade brasileira e que configuram um misto de infortúnios para sujeitos a depender de seu status social e/ou sua cor (DAMATTA, 1987).

Outro fator, que me chamou a atenção, foi que apesar da pandemia a violência policial ainda era o maior fator de apreensão, uma vez que diferente do vírus, que até aquele momento de 2020 ainda parecia uma ameaça distante e invisível, o caverão continuava, via incursões policiais, deixando seu rastro de mortes. Que explicitam práticas como ressalta Rodrigues, que debruçou olhar sobre a letalidade violenta policial também nesse momento de pandemia, que possuem particularidades em relação aos significados da morte, que não podem ser universalizadas (2021, p. 189-218).

Situações extremamente concretas e palpáveis para os moradores do Vale. Por outro lado, os mercados de venda de drogas ilícitas no varejo em um primeiro momento ficaram suspensas. Isso nas primeiras semanas de anunciada a pandemia, pois os traficantes locais com o medo inicial em relação ao vírus estabeleceram uma espécie de lockdown. No entanto, com o tempo desistiram de tais ações de alguma forma seguindo as representações que também serão aqui descritas a respeito da ameaça do vírus.

Após o primeiro momento, as precauções e medidas parecem ter sido relativizadas. $\mathrm{Ou}$ tal movimento, apenas explicitou as condições e problemáticas de vida enfrentadas pelos moradores do Vale, que se demostraram para além da questão que envolve os conflitos armados entre policiais e traficantes locais. Com isso, a necessidade de trabalhar, a manutenção das relações sociais e a sensação de que não há muitas outras saídas expressam traços marcantes da cidadania, ao passo que parecem compor os riscos que podem expor o morador do Vale tanto ao Corona Vírus, quanto as diversas formas de se morrer naquele contexto. 


\section{O CAVERÃO E CORONA VÍRUS: A CONSTRUÇÃO DE UM "DEU MOLE" COLETIVO}

Durante esses meses de pandemia, as operações policiais foram intensificadas, segundo os moradores do Vale. Evidentemente que a maioria delas parecem não preceder de registros (SILVA, 2014) oficiais ${ }^{5}$. Inclusive, em uma dessas operações, um policial chegou a ser alvejado. A notícia correu no whatsapp, circularam vídeos do policial baleado sendo socorrido por um colega de profissão. Interessante que segundo alguns dos "crias" do Timor Leste, os traficantes poderiam ter até matado os dois policiais, mas essa não era uma atitude desejada pelo Mano, que é a liderança local do tráfico (SILVA, 2019, 144-154). Isto pelo fato de que tal atitude poderia repercutir em mais invasões. Segundo João um dos rapazes que conversei, o policial fora baleado acidentalmente quando bateu de frente com "um bonde de rapazes de fuzil". Ali era atirar ou morrer. Então "eles teriam largado o dedo" e depois fugido.

Apesar disso, parece que a estratégia do Mano não deu muito certo. Pois, foram semanas de incursão policial naquela região após esse episódio. Eu tive notícia de uma série de pessoas que foram baleadas, dentre trabalhadores, adolescente que ficavam de vigias e traficantes. $\mathrm{O}$ Gordão que era pedreiro, 37 anos, pai de 3 filhas, foi uma dessas vítimas. Foi atingindo por um tiro do caverão quando saia as 5 horas da manhã de casa para trabalhar. Sua morte repercutiu no facebook e muitos moradores ficaram revoltados tratando o fato como "uma tremenda covardia". Porém, apesar das manifestações nas redes sociais nenhum movimento de reinvindicação organizada se formou. Segundo os moradores a versão policial foi de que não houve incursão no Vale naquele dia.

Durante essas semanas, contabilizei ao menos 15 mortes, seja por balas perdidas, via execuções e trocas de tiro com o caverão. Passado esse momento mais crítico, as incursões continuaram a acontecer semanalmente, pois a polícia manteve o cerco naquela localidade. Em uma delas 5 adolescentes foram mortos e tiveram suas fotos espalhadas pelos grupos de whatsapp de moradores do Vale. Pensei em trazê-las aqui, camuflando a identidade em respeito aos familiares. No entanto, mesmo assim as imagens eram chocantes em demasia. Aliás, balas

5 Apesar da fala dos moradores plataformas como o aplicativo "Fogo Cruzado", que é acessada pelos moradores, apresentaram uma queda nos tiroteios nos 5 primeiros meses de pandemia (vide: https://fogocruzado.org.br/relatorios-rj/) (última visualização em 20/03/2021). De fato, quando retornei ao Vale pude confirmar a intensificação das operações e tratarei disso mais adiante. 
de fuzil fazem "estragos sinistros" em qualquer ser humano.

As incursões policiais não paravam e as rotineiras mortes me eram informadas. Nesses momentos eu só me lembrava da fala de Jonas. Ele tinha sua razão ao relatar que o caverão vírus era uma ameaça real. Evidente que o termo "incursão" não é destituído de significância, uma vez que um dos seus significados representa a ação militarizada sobre um território estrangeiro ou considerado inimigo ${ }^{6}$. Ao passo que para os moradores que "tem nada haver com essa porra toda e quem tem sua vida invadida", como me repetia o Coroa, um Senhor de 70 anos e que foi um dos principais interlocutores nesse movimento de pesquisa, consolida uma série de situações embaraçosas. Ao conversar com moradores que tentavam fazer a quarentena, principalmente aqueles que haviam tido parentes e pessoas próximas mortas a partir do contágio com o Corona Vírus, percebi que no Vale há invasões constantes nas possibilidades de isolamento. Seja pela polícia, seja pela necessidade de trabalho, seja pelas relações de proximidade, festas, eventos da igreja e do tráfico e os conflitos que tais relações podem explicitar (SANTOS, 2016). E, como relata Santos (2016), isso é algo que é bem anterior ao momento de pandemia. Ou seja, o direito de se isolar não parece uma tarefa tão fácil para os moradores do Vale. Como me dizia, o Coroa, "tem gente que nem o direito de ficar em casa quieto pode ter".

Lúcia, de 29 anos, que é mãe solteira de um menino de 11 anos, segundo ela se apresenta, me relatou que era impossível manter a sanidade dentro de casa. As casas na sua rua, eram muito próximas e da sua sacada ela podia ver toda circulação na rua. E, nos dias de operação policial ficava ainda pior, pois o isolamento somando aos tiros mexia com sua sanidade mental. No seu caso, conseguia não trabalhar por conta do auxílio do governo, que segundo ela não dava para "comprar nada, mas pelo menos não faltava comida" e conseguia ficar em casa naquele momento em que não encontrava um trabalho.

Os relatos sobre mortes pelo vírus, continuaram acontecendo. No entanto, após alguns discursos que apontavam para a resistência física das pessoas, muitos moradores começaram a afirmar que o vírus só alcançava quem não tinha saúde. Em uma das conversas que tive com interlocutores, Daniel que a essa altura já me estava íntimo, perguntou quando eu voltaria para

\footnotetext{
6 "Incursão / in·cur·são / sf / 1 Invasão súbita de força militar em território estrangeiro ou inimigo; ataque, incorrimento, incurso, investida.(...)"(Dicionário de Língua Portuguesa Michaelis On Line, disponível em https://michaelis.uol.com.br/busca?id=okG9o) (última visualização em 20/03/2021).
} 
o Rio de Janeiro, já que eu, neste momento, estava no Mato Grosso. Eu lhe respondi que pretendia voltar nas férias, mas que ainda possuía muito receio por conta de tudo que estava acontecendo no Rio de Janeiro em relação ao vírus. Perguntei a ele como ele estava encarando isso tudo e o que ele fazia para se proteger, quando ele me deu a seguinte resposta:

\footnotetext{
"Cara não tem essa não.. aqui nunca teve quarenta irmão.. tá todo mundo bebendo na rua, indo pro baile, indo pra feira, ninguém parou nessa porra... não adianta ficar com medo não, o negócio é você cuidar da sua saúde e não ficar preocupado com isso se não é pior!"”
}

Eu questionei sua fala, dizendo que recebia informações de pessoas que tinham morrido e que isso não tinha relação necessariamente com a idade de ninguém como se falava no início da pandemia. O Daniel me disse: “tá maluco mano, pode vir, aqui só tá morrendo moribundo... só morre por essa porra quem já estava fudido, não conheci ninguém que tinha saúde que veio a morrer!"

Desde que me coloquei a pesquisar a produção sistemática de mortes em lugares chamados de favela, as justificativas para as mesmas se tornaram minha maior preocupação enquanto pesquisador. A ideia de "deu mole" que dialoga com a bruxaria para os Azande, evidencia um sofisticado conjunto de justificações em que "dar mole" aparecia como uma categoria aplicada desde o motivo da perda de uma mulher para outro morador até a justificação para se morrer ou matar, explicitando assim "um sistema de valores que regula a conduta humana" (EVANS-PRITCHARD, 2005, p. 56). Se o indivíduo levasse um tiro indo ao trabalho, sua morte era sentida e questionada, porém tal sentimento logo ganhava a alcunha de um "mole" (SILVA, 2019, p.154-160). Afinal, porque ele não ficou intocado, se sabia que estava acontecendo uma troca de tiros? Não foram poucos os casos que tomei nota a este respeito, afinal praticamente todos os dias alguém "dava um mole" ao morrer no Vale.

A fala do Daniel, somada as minhas reflexões e a continuidade da interlocução, me fizeram refletir se a questão da morte em relação ao Corona Vírus seguia o mesmo caminho. A justificativa de que não podia parar de trabalhar, que de fato é uma justificativa verídica, se somava a responsabilização da saúde dos indivíduos quando se pensava as mortes decorrentes do contágio do vírus. Em uma conversa com outro rapaz de 25 anos, o Anselmo, que era da 
igreja cristã protestante, ele chegou a me questionar o seguinte: "você tá com medo do vírus por que não acredita em Deus, para os homens de fé esse vírus não é nada! E você Gabriel, me responde... você não é um homem de fé?".

De fato, para alguns moradores, como Anselmo, a fé parecia um recurso viável, quiçá um dos poucos capazes de assegurar a aleatoriedade apresentada pelo contágio do vírus. Inclusive, gerando um movimento coletivo de enfrentamento as notícias e informações que circulavam na mídia. Outros interlocutores, também me afirmavam, tais como os integrantes do grupo do Timor Leste, que esse vírus só pegava gente "nutella", ou seja, aqueles "criados em berço ouro". Agora com a "galera aqui do grupo (de whatsapp dos crias do Timor Leste) que vivia na rua descalço, brincando em água suja, pulando muro e passando perrengue, essa porra de vírus não dá dentro não", como escreveu João, que trabalhava como técnico de manutenção de ar condicionado.

Diante de todos as problemáticas enfrentadas por aquelas pessoas, realmente o vírus parecia ser a menor delas. Em outra ponta, a fé, a questão da saúde e do estilo de vida, me parecem garantir no discurso um "deu mole" coletivo para aquelas pessoas. A opção do governo federal por não estimular o isolamento, principalmente por fatores econômicos, ganhava coro nas falas de meus interlocutores no argumento da necessidade de se comer e trabalhar. Com isso, indaguei se a política adotada para a "retenção" do vírus na cidade do Rio de Janeiro não implementava um "deu mole" coletivo. Ou seja, passando por essa visão econômica, a linha argumentativa aparentemente possibilitou uma construção social do "dar mole", intrínseco nas características físicas e individuais de cada um. Assim, se a noção de economia potencializava a questão da morte por um lado, as questões sanitárias, problemas de saúde pública e o desconhecimento em relação ao vírus ameaçava potencializar as mortes pelo outro.

Naquela região do Vale, a forma de viver e morrer atribuída por um tratamento especializado, decorrente da gestão pública do Estado para populações subalternas (RODRIGUES, 2021), era obscurecida pela condição física de cada um em relação ao vírus. Como continuou o Daniel: "a Covid mata quem tá aqui mano? Não! Claro que não. Aqui a gente morre mesmo é de tiro! A Covid aqui só tá levando quem já tinha que morrer mesmo, quem já estava no seu tempo no plano de Deus".

Assim, o "mole" para quem morresse pelo Corona Vírus já estava construído, se você não tem fé, se você já era um moribundo... De certo a relação com o caverão, também explicita 
a proximidade com a morte. Afinal o que representa a morte para quem tem sua vida nesse contexto de estrema violência estatal? O que ficou mais intenso após o episódio de conflito narrado no início desse tópico. O impacto do recrudescimento das ações policiais, também inspirou em táticas de defesa por traficantes, como bloqueio de ruas e a escolta de carros considerados "estranhos" nas principais ruas do Vale. Em meio a tudo isso ficaram os moradores do Vale, que dentre outras problemáticas enfrentavam a desigualdade das políticas de ensino a distância das escolas públicas. A dificuldade de atendimento emergencial para casos mais graves de COVID-19. A falta de empregos formais, ao certo que diversos interlocutores perderam seus empregos ou tiveram seus salários reduzidos. Ou seja, a construção de um cenário ideal para se dar um mole.

\section{AS RELAÇÕES DE PROXIMIDADE QUANDO "CADA UM SE PROTEGE DA MANEIRA QUE PODE"}

No período de dezembro de 2020, acabei sendo confirmado com a COVID-19. A suspeita é de que eu tenha sido contaminado durante o voo de avião do Mato Grosso para o Rio de Janeiro. Difícil foi me manter isolado das pessoas no Vale. As pessoas iam me ver e me chamar no portão de casa, caso estivesse aberto até entravam. Evidentemente, quando tinham mais intimidade. Algumas afirmavam estar cientes, outras diziam já ter pego a doença. Paulo, um rapaz de 30 anos que alugou uma casa ao lado da minha. Destaca-se que nossas casas se encontram no segundo andar de outras casas. Ou seja, somos vizinhos de segundo andar. As conversas se davam comigo da sacada da minha casa e ele da janela de frente da casa dele. Ele me disse que eu teria que ser mais incisivo e trancar o portão e falar seriamente com as pessoas sobre a questão de que eu estava com suspeita de COVID-19. Afinal, fazia algum tempo que eu não voltava ao Vale e amigos e pessoas próximas estavam sempre me chamando no portão para me rever.

A estratégia indicada por Paulo deu certo. E, com isso consegui cumprir minha quarentena, ao menos enquanto me recuperava da doença. Com o tempo comecei a perceber que o isolamento no Vale, guardava semelhanças com a forma de se isolar na cidade que eu 
estava residindo anteriormente no Mao Grosso7. Havia um controle diário do estado de saúde das pessoas próximas. O monitoramento também se dava em relação a circulação e responsabilidade e irresponsabilidade a respeito da conduta uns dos outros. Principalmente aqueles que figuravam como parte do que seria considerado um grupo de risco. Ou conforme dito por Daniel e relatado aqui anteriormente, aqueles que fizessem parte do grupo "dos moribundos".

Do lado oposto a casa de Paulo, um bar fora aberto. Esse bar cumpre a estética de um boteco. Com uma entrada cerrada por uma porta de ferro dessas de correr de cima para baixo. A pintura de escudos de times do Rio de Janeiro. Um balcão que divide lateralmente o espaço de circulação dos clientes entre o banheiro e os freezers de bebidas. Os clientes costumam sentar na parte externa, que possui uma cobertura de telhas de alumínio e tem na calçada uma extensão do bar. Da sacada da minha casa posso ver o bar e posso afirmar que em nenhum momento desde que retornei ao Rio de Janeiro o mesmo fora fechado por conta da pandemia, a recíproca não é verdadeira em relação ao caverão. O que também não significava que as pessoas que frequentavam o bar estivessem totalmente despreocupadas em relação a COVID-19.

A essa altura ninguém parecia desafiar a capacidade do vírus. Pude conversar com Seu Guto de 69 anos, que trabalha como pedreiro e segundo ele mesmo "quase morreu por conta dessa doença". Ele ficou internado, precisou de respirador e ficou mais de 20 dias no hospital. Finalizou sua fala dizendo para mim que não podia pegar novamente essa doença. Então, o indaguei pelo motivo de estar ali no bar. Ele disse que assim como eu que estava no meu portão falando com ele, mas entendendo que estava tomando o devido cuidado, ele também o fazia. Os outros senhores que estavam no bar, confirmaram a versão do Guto, e começaram a relatar casos de COVID-19. Alguns com superação da doença e outros não. Apesar de os frequentadores do bar serem normalmente idosos e de todos estarem no local sem máscara, de alguma forma cada um dos 6 senhores ali presentes afirmavam estar se cuidando da maneira que podiam. Aliás, tal afirmação era constante entre os moradores do Vale.

Juliana, 26 anos, que conheci enquanto fazia pesquisa para o doutorado estava trabalhando em um estabelecimento com bar e piscina, que ficava em uma área próxima ao Vale. Em uma conversa comigo via o aplicativo do whatsapp, ela me relatou que um de seus chefes que ficava responsável pelo local que ela trabalhava, chegou para ela e mostrou que

\footnotetext{
${ }^{7}$ A Cidade de Barra do Bugres, possui pouco mais de 30 mil habitantes e tem em uma usina de cana de açúcar uma das maiores fontes de emprego. Situada às margens do Rio Bugres, um afluente do Rio Paraguai a maior parte do território é composto por plantações de cana de açúcar, bem como outros cultivos em menor escala.
} 
estava com COVID-19, entregando-lhe o exame. A primeira atitude de Juliana foi indagar, “como assim"? O patrão respondeu que estava tudo bem, que não sentia nada. Juliana me disse que ficou em pânico, que começou a pensar no filho de 2 anos dela, no seu marido que trabalhava como motorista de aplicativo e na sogra de 50 anos que havia encontrado em um almoço 2 dias antes. Ela sempre me chamava para ir na piscina, porém como eu nunca ia, nesse dia ela me mandou a mensagem, me dizendo que realmente eu estava certo em não ir. Porém, passados alguns dias ela disse que nada sentiu, que seu patrão também ficou tranquilo e que estava tudo bem.

Conversando com Jonas, ele me relatou que a maioria das pessoas que descem com ele da condução, vem de máscara de outras áreas da cidade, mas conta os segundos para descer no Vale e retirar o objeto dito como sufocante. De alguma forma estar no Vale parece indicar um espaço de familiaridade que para alguns explicita a possibilidade de exercer sua identidade. Para o Jonas, isso se expressava na liberdade de poder tirar a máscara tranquilamente, como um direito seu.

Apesar de todo receio, também circulei no baile funk. Realmente a primeira impressão era de que não havia tantas pessoas como antes. Fiquei receoso e estava com máscara, quando fui abordado por um grupo de amigos que me disseram de forma jocosa, "se veio pro baile é pra vir sem neurose de Corna Vírus!”. Apesar dessa fala, muitas pessoas estavam de máscara. Porém, a maioria esmagadora não estava. Conversei a respeito do baile funk com o Daniel, que me referi acima, e ele me disse que na visão dele "baile funk nunca parou, que as raves nunca pararam, que os pagodes e bares nunca pararam de fato no Rio de Janeiro". Essa fala foi anterior ao carnaval. Porém, diferente dos últimos anos, em 2021 não aconteceram os bailes de carnaval que costumavam começar 15 dias antes do feriado e terminar 15 dias depois no Vale, sempre de quinta-feira a domingo. Tal baile era registrado na lista da Prefeitura da Cidade e por conta disso, nem pagando arrego (RODRIGUES, 2021) para os policiais seria possível acontecer a festa esse ano.

Com isso, comecei a perceber que no Vale cada um tem se cuidado em relação a COVID-19 da forma que pode. Estabelecendo crenças e saberes em relação ao vírus que se constroem na dialética entre as informações produzidas pelos veículos de impressa e aquilo que se observa no dia a dia de cada um. No momento que estava Mato Grosso, imaginei que houvesse um descaso total em relação ao vírus, mas quando cheguei ao Rio de Janeiro, a minha experiência no Vale demonstrou que as pessoas estão se relacionando com a pandemia a partir 
do sistema de crenças que lhes é disponível. Como no caso da continuidade das atividades nas igrejas e terreiros, com aglomeração geralmente de pessoas de idade. Que pautam a fé como melhor forma de não se contaminar pela COVID-19.

Carlos, 33 anos, que conheci por ser um entregador de pizza que levou um pedido meu, me contou que ele e seu pai quase morreram no dia da vacinação dele. Seu pai um idoso de 75 anos, estava na maior expectativa de ter chegado a sua hora de se vacinar. E, Carlos não via a hora da vacina, uma vez que seu pai não saia da igreja. Acontece que na data estipulada para pessoas da idade do pai de Carlos, aconteceu uma incursão policial, que segundo moradores, chegaram a circular pela região mais de um caverão. Eu ouvi muitos tiros de casa e vi o veículo blindado da Polícia Militar passar duas vezes na minha rua. O barulho é realmente assustador. Figura como um tanque de guerra, levantando poeira e causando aflição nos segundos em que você o acompanha passar. Isso se ele simplesmente passar, pois para muitos o encontro com tal aparato do Estado pode te levar a morte.

Nesse dia, apesar dos tiros e de todo clima de guerra que tomou o Vale, não soube de nenhuma notícia de pessoas mortas ou feridas em algum conflito. A questão é que os veículos passaram toda manhã circulando no Vale e os traficantes locais responderam colocando barreiras para circulação dos mesmos. Carlos me disse que não tinha visto a nova barreira quando saia para o posto, quando manobrou seu veículo (ele estava de carro) para dar meia volta, avistou o caverão e então começou uma intensa troca de tiros. Segundo seu relato, só deu tempo de encostar o carro e se abaixar. Passado o susto, recebeu a informação de que haviam várias barreiras e que por conta do conflito não haveria vacinação no posto de saúde do Vale. Ele me disse que só conseguiu vacina para seu pai no posto de saúde do bairro vizinho, quase no final do plantão. Para ele só foi possível a vacina pela sorte de ter também sua moto, já que "muitos idosos conseguiram se vacinar por causa dessa bagunça toda".

Aqui a questão a respeito da cidadania, aparece em meio a relações de proximidade e um contexto de desigualdade. No entanto, os índices em relação a morte pela COVID-19 não pararam de crescer em 2021. Ao passo que a situação não parece nada bem, pesquisas disponibilizadas por veículos de informação apontam para altos números de mortes por $\operatorname{dia}^{8} \mathrm{e}$

8Informação retirada do sítio virtual: https://g1.globo.com/bemestar/coronavirus/noticia/2021/03/28/brasilregistra-novo-recorde-na-media-movel-com-2598-mortes-diarias-por-covid.ghtml; (ultima visualização em 26/03/2021) 
até a data da escrita deste artigo para marca de $312.206^{9}$ casos de pessoas mortas pela doença no Brasil. Em meio a questionamentos e a disputas políticas em relação a tais dados, as mortes em lugares chamados de favela, podem ter alcançado índices maiores do que de alguns países ${ }^{10}$ ao redor do mundo. Apesar de não ser o objetivo do trabalho uma análise de cunho quantitativo, tais dados são informações que circulam entre as pessoas do Vale. São frutos de discussão e aparecem nos questionamentos daqueles que desenvolveram suas formas de se cuidar, bem como daqueles que pautam na sua observação empírica a desnecessidade de cuidado.

\section{A QUESTÃO DA FÉ E A CIDADANIA TRANSITÓRIA: QUANDO A DESUMANIZAÇÃO É A LÓGICA DE CONTROLE}

Como já referi, uma das minhas pretensões com esse movimento de pesquisa era a de entender como e para quem se distribui a garantia da proteção do direito à vida em um momento como esse, de pandemia. Portanto, a questão da cidadania me parece apontar para a relação entre trabalho, fé, vida e morte. O nosso sistema de justiça, bem como as agências de estado, tem na perspectiva do Direito uma relação geracional com a cidadania. De fato, a reflexão a respeito de "dogmas", "doutrinas", autores e instituições jurídicas, bem como de atores sociais empenhados em (re)produzir tais concepções, expressam a cidadania como um conceito legal. Além da percepção de suas gerações, em que pesem direitos socais, civis e políticos, o voto e a carteira de trabalho são diacríticos marcantes para a cidadania no Brasil. Principalmente em uma perspectiva estritamente jurídica.

A linha de reflexão a respeito da relação com a vida, a morte e a fé me parece capaz de suscitar questões que mostram a transitoriedade do ser cidadão para inúmeras pessoas. Como já expliquei, não é objetivo desse trabalho questionar as ideias de cidadania postas, mas inaugurar um estudo que pretende refletir a respeito da compreensão da figura do que representa ser cidadão a partir da análise da realidade social e dos fenômenos sociais e jurídicos que nela ocorrem. Com isso, além de permitir a percepção de que o direito e a cidadania também podem

\footnotetext{
9 Informação retirada do sítio virtual: https://www.cnnbrasil.com.br/saude/2021/03/28/brasil-registra-domingomais-letal-da-pandemia-com-1656-novas-mortes; (última visualização em 26/03/2021)

10Informação retirada do sítio virtual: https://www.cartacapital.com.br/sociedade/favelas-do-rio-registram-maismortes-por-covid-19-que-muitos-paises/; (última visualização em 26/03/2021)
} 
ser produzidos a partir de relações sociais e institucionalmente estabelecidas. A ideia não é desvalorizar o que já vem sendo produzido nos livros e "doutrinas" jurídicas, e sim dedicar especial atenção ao processo de como essas ideias podem ser compreendidas de forma diversa à instituição de um dogma e/ou sua reprodução irrefletida. Até pelo fato de em uma perspectiva jurídica o direito à vida ser um direito fundamental, que não é o que parece acontecer para os moradores do Vale.

Entendo, que a pesquisa empírica representa uma via necessária ao processo de compreensão da produção do conhecimento, onde o direito e a cidadania são colocados como objetos de pesquisas, que pretendem entender determinadas questões a partir das ações de seus atores sociais. De modo a refletir a respeito da ideia, por exemplo, de que a cidadania é produzida, de um lado, nos tribunais a partir das decisões proferidas por seus magistrados e, de outro, a partir de um processo de constitucionalização do debate político e jurídico. $\mathrm{O}$ que permite tencionar seu caráter vertical, onde apenas seja reconhecida como exercício da cidadania aquilo que uma "elite" intelectual diz o que é ou deveria ser.

A reivindicação por uma nova agenda de pesquisa que relacione práticas do viver ao discurso jurídico sobre cidadania, pode representar uma mudança de perspectiva, onde se atribuirá olhar atento às regras, princípios, teorias, teses, argumentos capazes de se reproduzir no cotidiano das relações sociais seus sentidos e significâncias. Ampliando a reflexão a respeito de uma organização pragmática da sociedade e suas instituições.

Essa mudança de perspectiva é um dos objetivos que essa discussão propõe. Afinal, a relação coletiva com a possibilidade da morte para uma população que vive em lugares chamados de favela parece aplicar um "deu mole" coletivo. Em que a morte é uma consequência natural, seja via a atuação do aparelho repressivo do Estado ou via o descaso em relação a saúde já estabelecido e evidenciado em tempos de pandemia. A Carteira de Trabalho e o direito/dever de votar me parecem marcar uma cidadania transitória com a chancela da desigualdade que estrutura a sociedade brasileira. Afinal, se ser cidadão tem sua relação com tais diacríticos, por outro lado viver pela perspectiva da morte, torna uma série de vidas vulneráveis a justificativas para suas potenciais mortes que recaem sobre a responsabilidade de quem morreu. Aliás, você “deu mole”, você era um moribundo, você não tem fé o suficiente. 


\section{CONSIDERAÇÕES FINAIS}

Procurei aqui abordar questões que se conectam com a desigualdade revelada na vida de um cem número de pessoas na Cidade do Rio de Janeiro. O panorama da pandemia trouxe uma necessidade de isolamento social e ganhou contornos dramáticos em uma sociedade em que manter-se seguro em relação ao vírus se tornou um privilégio. Enquanto uma pequena parcela da população ainda se mantém em isolamento outra significativa parcela, desde o início da pandemia, luta para manter seus trabalhos, suas rendas e até mesmo sua vida.

No movimento de pesquisa que originou este artigo, pude conversar como pessoas, que entre perder seus trabalhos e/ou deixar de fazer suas atividades para se proteger do Corona Vírus (COVID-19), sequer cogitaram a segunda possibilidade enquanto uma opção. Enquanto professor e pesquisador posso exercer meu trabalho de casa, mas a realidade brasileira aponta para milhões de pessoas infectadas pelo vírus e para centenas de milhares de mortes.

Aqui, pude explicitar que justificações para as mortes se apoiavam na conduta do indivíduo que morreu. Afinal, "quem morreu é porque que deu mole" (SILVA, 2019, p. 154160). Com a pandemia, devido ao COVID-19, tais localidades que são foco de políticas repressivas e de extermínio de pessoas, passaram a ser de minha preocupação devido aos impactos da doença. Nesse jogo de quem pode morrer, os trabalhadores estão necessitando pegar conduções e se expor nas ruas. O vírus aparece como mais uma das ameaças enfrentadas pelos moradores do Vale, ao passo que as rotineiras práticas policiais como incursões do caverão continuam produzindo mortes mesmo em meio a situação que toda sociedade enfrenta.

Imagino que pude tatear o motivo pelo qual, de acordo com as representações dos moradores do Timor Leste, a preocupação com o caverão parece ser maior do que a preocupação com o contágio e eventual morte pelo vírus. Fatores que estimulam a discussão em relação ao sistema de justiça estabelecido para pessoas que moram em lugares chamados de favela. Como pude perceber o judiciário encabeça um afastamento sobre a coerção ou julgamento de vítimas da ação estatal que tem como braço final a polícia. Apesar da garantia igualitária do direito à vida, em nossa Constituição Federal de 1988, as mortes não são reclamadas e, por conseguinte não informam preocupação do sistema de justiça criminal. Legitimando-se na conduta de quem morre, como na questão da ideia de "deu mole", as 
motivações e até a necessidade de se produzir tais mortes. Além de uma série de fatores que se implicam em um sistema de crenças e saberes que englobam a fé, a necessidade de trabalhar e as relações proximidade.

Por fim, pude refletir a ideia de como a produção sistemática de mortes e a sua naturalização é próxima a realidade daquelas pessoas, uma vez que reverberam em suas práticas sociais em espaços públicos com uma mínima proteção de direitos humanos e de cidadania. $\mathrm{O}$ Corona Vírus fora anunciado "como um vírus de todos", portanto no imaginário das pessoas que conversei é uma questão de sorte ou azar adquirir e principalmente morrer como vítima da doença. Algo que se tiver que acontecer vai acontecer e ninguém vai poder evitar. Como no caso de trabalhadores que precisam pegar condução lotada e não tinham o privilégio de abrir mão de seus empregos. Assim como a rotineira violência policial, já que a figura do caverão que não é para todos, reafirma que tal tratamento do Estado é o apropriado para aquelas pessoas. Afinal, conforme esta pesquisa conseguiu verificar o "caverão vírus pega mesmo" e me parece que a COVID-19 também. O que se torna ainda mais evidente pelo fato de que o isolamento social é uma conquista de quem de fato é visto como cidadão em tudo que essa ideia representa na Cidade do Rio de Janeiro.

\section{REFERÊNCIAS BIBLIOGRÁFICAS}

ABREU, Luiz Eduardo. Etnografia constitucional: quando o Direito encontra a Antropologia. In "Os bastidores do Supremo e outras histórias curiosas: estudos de etnografia constitucional". Organização de Luis Eduardo Abreu. Brasília: UniCEUB, 2013.

BOURDIEU, Pierre. O poder simbólico. 2ª ed. Rio de Janeiro: Bertrand Brasil, 1998.

As condições sociais da circulação internacional das ideias. In: Atos de pesquisa em Ciências Sociais, 2002. Tradução de Luiz Felipe Martins Candido.

CARDOSO DE OLIVEIRA, Luis Roberto. A Vocação Crítica da Antropologia. Anuário Antropológico/90. Rio de Janeiro: Tempo Brasileiro, p. 67-81, 1993.

Direito Legal e Insulto Moral: Dilemas da Cidadania no Brasil, Quebec e EUA. Rio de Janeiro: Relume-Dumará, 2002.

CARVALHO, José Murilo. Cidadania no Brasil: o longo caminho. Rio de Janeiro: Civilização Brasileira, $3^{\text {a }}$ ed., 2002. 
CASTRO GOMES, Ângela Maria de. A invenção do trabalhismo. Rio de Janeiro: Editora FGV, 2005.

CORREA, Claudia Franco. Trabalho publicado nos Anais do XVII Congresso Nacional do CONPEDI, realizado em Brasília - DF nos dias 20, 21 e 22 de novembro de 2008. P - 995116.

CLIFFORD, James. A experiência etnográfica: antropologia e literatura no século XX. 2. ed. Rio de Janeiro: Editora UFRJ, 2a ed., 2002.

DAMATTA, Roberto. Digressão: a fábula das três raças, ou o racismo a brasileira. In.: DAMATTA, Roberto. Relativizando: uma introdução a antropologia social. 5. ed. Rio de Janeiro: Rocco, 1987.

EVANS-PRITCHARD, E. E.. Bruxaria, Oráculos e Magia entre os Azande. Rio de Janeiro: Jorge Zahar Editor Ltda., 2005.

FREIRE, Jussara. Agir no regime de desumanização: Esboço de um modelo para análise da sociabilidade urbana na cidade do Rio de Janeiro. Rio de Janeiro: Revista Dilemas, v. 3, n. 10, 2010.

FOOTE-WHITE, William. Sociedade de Esquina. Rio de Janeiro: Jorge Zahar, 2005.

GOFFMAN, Erving. Interaction Ritual: Essays in face to face Behavior. New York: Doubleday, 1967.

1975.

A representação do eu na vida cotidiana. Editora Vozes: Rio de Janeiro,

KANT DE LIMA, Roberto. Sensibilidades jurídicas, saber e poder: bases culturais de alguns aspectos do direito brasileiro em uma perspectiva comparada. In Anuário Antropológico/2009 - 2, 2010: 25-51, 2010.

LENOIR, Remi. Objeto Sociológico e Problema Social. In: CHAMPAGNE, Patrick et al. Iniciação à Prática Sociológica. Petrópolis: Vozes, 1998.

MARSHALL, T. H. Marshall. Cidadania, classe e status. Rio de Janeiro: Zahar Ed., 1967.

MBEMBE, Achille. Necropolítica. Rio de Janeiro: Artes \& Ensaios, Revista do PPGAV/EBA/UFRJ, n. 32, dez, 2016.

SANTOS, Solano Antonius de Sousa. “Tá tranquilo, tá favorável?" - Ordem Pública e Violência Social em uma perspectiva etnográfica. 2016. Dissertação (Mestrado em Direito Constitucional), Faculdade de Direito, Universidade Federal Fluminense, Niterói, Rio de Janeiro, 2016.

SILVA, Gabriel Borges. "Quantos ainda vão morrer eu não sei”: o regime do arbítrio, curtição, morte e a vida em um lugar chamado de favela. Tese (Doutorado) - Universidade Federal Fluminense, Programa de Pós-Graduação em Sociologia e Direito, Faculdade de Direito, 2019. Orientador: : Lenin dos Santos Pires. Coorientador.: Rômulo Bulgarelli Labronici. 
SILVA, Gabriel Borges; FREIXO, Alessandra Soares. Camelôs, autoridades e Mercado Popular da Uruguaiana: uma analise sobre a precariedade na utilização do espaço público. Trabalho apresentado na $29^{a}$ Reunião Brasileira de Antropologia, Natal/RN, 2014. Disponível em:

http://www.29rba.abant.org.br/resources/anais/1/1402015385_ARQUIVO_Artigo_29RBA__Camelos,autoridadeseMercadoPopulardaUruguaiana_-_Gabriel_-_.

. PEREIRA JUNIOR, Fabio Garcia. ; ROSA, Natalia Pinho. Cidadania e justiça criminal: quando "sair da linha" implica no não acesso a direitos civis. In: Direito à Cidade: Regularização Fundiária, Rio de Janeiro: Editora Multifoco, $1^{a}$ Edição, Agosto de 2017.

VELHO, Gilberto. Observando o familiar. In: Individualismo e cultura: notas para uma antropologia da sociedade contemporânea. Rio de Janeiro: Jorge Zahar, 1980. 